\title{
The Monitoring of Temperature Effect on the Supporting Structure of Main Active Reflector for FAST
}

\author{
Wang Qingmei, a , Zhu Ming ${ }^{1}$, Wang Qiming ${ }^{1}$, Yang Lei ${ }^{1}$, Lei Zheng ${ }^{1}$ \\ ${ }^{1}$ National Astronomical Observatory, Chinese Academy of Science, Beijing 100012, China \\ âwangqingmei@bao.ac.cn
}

Keywords: FAST engineering, Health monitoring, Temperature effect, Polynomial regression.

\begin{abstract}
The variations of ambient temperature can change the state of the supporting structure of the reflector for Five-hundred-meter Aperture Spherical Radio Telescope. The purpose of this research is to monitor the temperature and the varieties to find their relationship. Firstly, the temperature monitoring system is introduced. Then, this study proposed a temperature analysis method based on the polynomial regression technique. After that, the influences of the non-uniform temperature field brings by the sunshine to the ring beam is presented. Meanwhile, the relationships between the variations of the stress for ring beam, the shape of ring beam and cable forces with temperature changes are figured out. The results reveal that the temperature field of the ring beam under sunshine is non-uniform, but the temperature difference is less than $6^{\circ} \mathrm{C}$. However, the seasonal temperature difference has great influence on the shape of ring beam and the force of main cables. These results provide useful support for the future monitoring and safety assessment of supporting structure for FAST.
\end{abstract}

\section{Introduction}

Five-hundred-meter Aperture Spherical radio Telescope (FAST) is the largest single-dish radio telescope located at a Karst depression in the south of Guizhou province [1]. As one of three critical innovations of FAST, the main active reflector system is composed of ring beam, reflector elements, actuators, cables and anchors [2,3]. As the main support structure, ring beam is supported by Lattice columns. The cable-net is weaved by 6,670 main cables which are formed by 2,225 cable joints. Each joint connects to a pull-down cable and an actuator. Fig. 1 is the entity diagram of FAST.

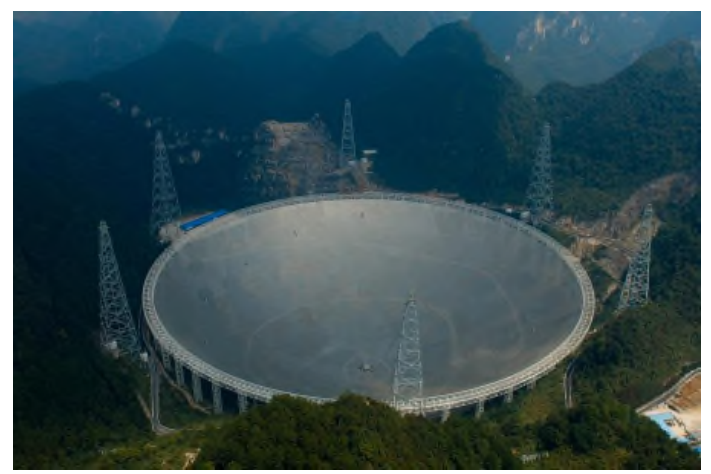

Fig. 1 The entity diagram of FAST.

The state of the ring beam and lattice column plays a key role in the safety of the entire cable-net and the shape accuracy of the reflecting surface. In order to ensure the normal operation of FAST, it is necessary to monitor its structural response and environmental conditions, especially the effect of temperature on the structure. Jin Xiaofei et al. [4] establish an integral parametric finite element model for the supporting structure of the FAST reflector and its measured landform based on the thermal analysis module of ANSYS. A research on the effect of non-uniform temperature field 
under sunshine on the fitting accuracy of the reflector is also carried out. This study is focused on the effect of temperature on the supporting structure of the reflector for FAST based on the monitored data collected from temperature monitoring system. Firstly, the preliminary introduction for the temperature monitoring system is described. Then, the temperature effect analysis model is established. After the pre-processing of the collected data, a reliable database can be built. In addition, the statistics of effective temperature and structural response are figured out. Finally, the variations of the stress for ring beam, the shape of ring beam and cable force with the temperature is presented.

\section{Temperature Monitoring System}

The Temperature has a significant impact on large steel structure, for instance, the temperature variations can cause the thermal expansion and contraction of the ring beam, as well as the stretching and shortening of cable length. Through the monitoring of the ambient temperature and the temperature field of structural members, it is possible to analyze the influence of temperature on the stress state of the whole ring beam, the shape changes of ring beam and cable forces of typical main cables. The health monitoring system for the main reflector of FAST includes five sub-systems, which are sensory system, data acquisition and transmission system, data processing and analysis system, data management system, and the structural health assessment system. The sensory system is consists of 506 sensors. This study is focused on the effect of temperature on supporting structure of the reflector. Therefore, only the pertinent monitoring system and measurement points related with temperature sensors, strain gauge and cable force sensors are introduced in this thesis. The 406 temperature measurement points of cable-net combined with cable force sensors are shown in Fig. 2 (a). The other 100 temperature monitoring points of ring beam and lattice columns combined with stress sensors are shown in Fig. 2 (b) and (c).

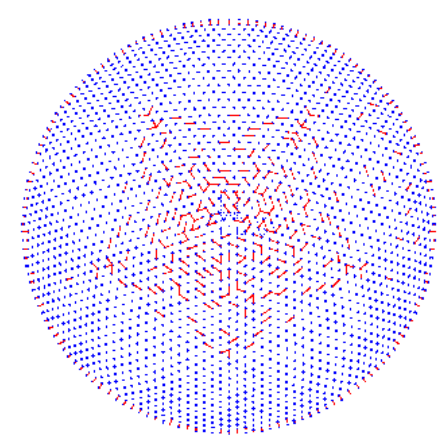

(a) The cable-net

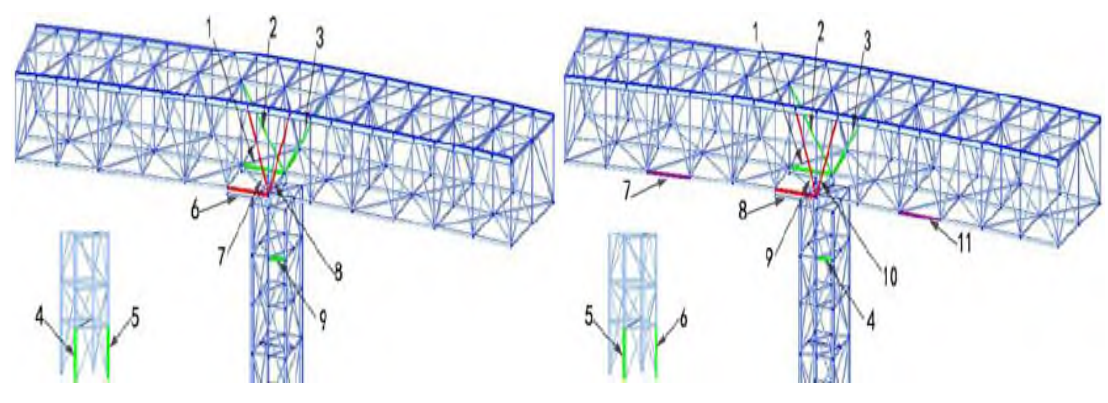

(b) corresponding ring beam of $1 \#, 11 \#, 21 \#, 31 \#, 41 \#$ lattice columns (c) corresponding ring beam of 6\#,16\#,26\#,36\#,46\#lattice columns

Fig. 2 The Arrangement of monitoring points.

\section{Analysis Principles}

Data Pre-processing. The collected original data sometimes may be disturbed by malfunction of sensors, environmental noise and other factors. Therefore, the collected data should be pre-processed. There are four data elimination methods which are $3 \sigma$, Grubbs, Dixon and Chauvenet criteria. For the health monitoring system of the main reflector for FAST, the $3 \sigma$ criterion is suggested to eliminate the abnormal data, and then the method of Lagrange interpolation is used to interpolate. The $3 \sigma$ principle is based on the statistical theory, whose expression is shown as

$$
\left|x_{i}-\bar{x}\right|>3 \sigma
$$

In the type: $x_{i}$ means a measured data; $\bar{x}$ is arithmetic mean of a set of measured data. When a 
data conforms to the above formula, it is judged as an abnormal point and should be eliminated. Among a set of data sequences, there might be more than one abnormal data, after removing an outlier, the mean and standard deviation of the remaining data should be recalculated to re-judge the remainders, until there is no outlier.

Temperature Parameters of Structure. In order to examine the effect of temperature on structure, effective temperature and temperature difference are introduced. Temperature difference refers to the difference between each adjacent cross-section along a direction of structure in terms of temperature. It plays a critical role in the internal force of structure. Effective temperature refers to the temperature change of the whole structure. It's a theoretical temperature calculated by weighting and adding temperature measured at various locations within the cross-section [5]. There are a maximum value and a minimum value in a certain time. The effective temperature of the ring beam can be calculated as

$$
T_{E}=\sum_{i=1}^{n} T_{i} / n
$$

In the type: $T_{E}$ is the effective temperature of structure; $n$ is number of sensors installed at various locations within the cross-section of structure; $T_{i}$ is the measured data.

Polynomial Regression. To facilitate the description of temperature effect on the supporting structure of the reflector for FAST, the statistical relationship among temperature, ring beam stress and cable force need to be established by the measurement data from health monitoring system for reflector of FAST. The temperature data, stress of the ring beam data and cable force data in the analysis are the hourly mean value of each monitoring point. After the pro-processing of each set of data, polynomial regression is used to establish the statistical relationship between parameters and temperature. The expression of the relationship is shown as

$$
\mathrm{y}=\beta_{0}+\beta_{1} T+\beta_{2} T^{2}+\mathrm{L}+\beta_{m} T^{m}+\varepsilon
$$

In the type(3): $T$ stands for the hourly mean value of temperature; $y$ stands for the hourly mean values of structure; $\beta_{i}(i=0: m)$ mean the regression parameters; $m$ stands for the order of polynomial.

\section{Analysis of Monitored Temperature}

Effective Temperature of Ring Beam. It is important to understand the range and distribution of the temperature of structural components. Monitored temperature parameter statistics include three aspects, which are the statistics of effective temperature of the ring beam, the analysis of the temperature difference under sunshine of the ring beam and the statistics of temperature field of the ring beam as well as cable net. As a large-scale structure, the reflector of FAST can consider the specification of bridge as reference in terms of effective temperature [6]. Table 1 displays the part of the specification which the steel structure should be complied with.

Table 1. Standard values of effective temperature for highway bridge.

\begin{tabular}{|c|c|c|}
\hline \multicolumn{3}{|c|}{ Steel bridge deck } \\
\hline $\begin{array}{c}\text { Temperature } \\
\text { subarea }\end{array}$ & Max-temp & Min-temp \\
\hline Severe cold area & $46^{\circ} \mathrm{C}$ & $-43^{\circ} \mathrm{C}$ \\
\hline Cold area & $46^{\circ} \mathrm{C}$ & $-21^{\circ} \mathrm{C}$ \\
\hline Warm area & $46^{\circ} \mathrm{C}$ & $-9(-3)^{\circ} \mathrm{C}$ \\
\hline
\end{tabular}

Note: The values in brackets of the table are applicable to the area of Kunming, Nanning and Fuzhou.

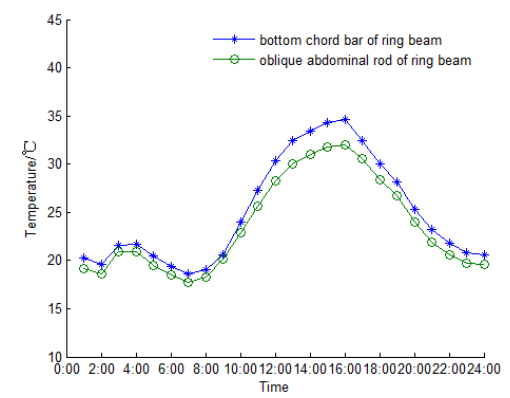

Fig. 3 Effective temperature-Time curve of the bottom chord bar and oblique abdominal rod of ring beam (April 16, 2016). 
The standards of effective temperature for high bridge shown in Table 1 indicate that the maximum design effective temperature which the reflector of FAST should complied with is $46^{\circ} \mathrm{C}$, the minimum effective temperature of reflector is $-9^{\circ} \mathrm{C}$. The effective temperature of structural components needs to be established based on the measurement data. The temperature data and parameters of structure during April 15, 2016 and May 16, 2016 are considered as the statistics of effective temperature of structural components. Fig. 3 shows the effective temperature of the bottom chord bar and the oblique abdominal rod of ring beam in a day.

Fig. 3 shows that the range of the effective temperature of structural components is within the design effective temperature. The variations and ranges of the bottom chord bar are similar with the oblique abdominal rod. The statistics of annual maximum and minimum effective temperature will be studied to facilitate the assessment of system safety in the next years.

Temperature Field of Structural Components. The large steel structure and steel cables are subjected to the effect of temperature induced by solar radiation and seasonal variations. In order to analyze the effect of the non-uniform temperature field under sunshine on the structure of ring beam, the shadow distributions bring by sunshine in April 16, 2016 are described as Fig. 4. In addition, the temperature field of the ring beams based on the hourly mean value measured in April 16, 2016 and January 10, 2016 are shown as Fig. 5 (a) and (b), Fig. 6 (a) and (b).

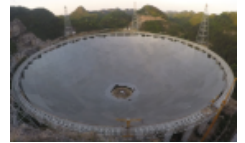

7:00

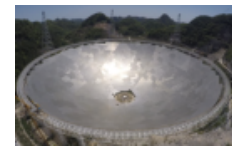

13:00

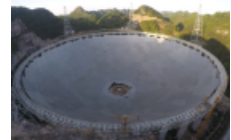

7:30

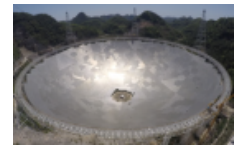

14:00

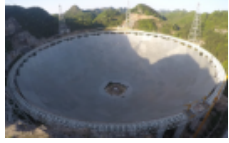

8:00

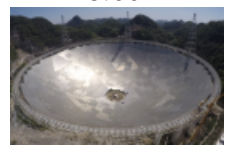

15:00

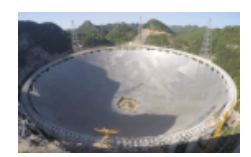

9:00

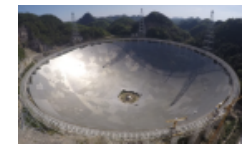

16:00

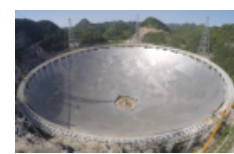

10:00

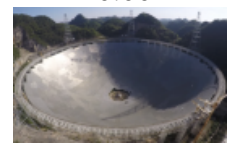

17:00

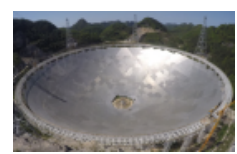

11:00

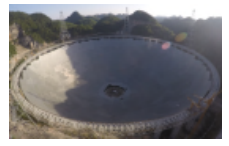

18:00

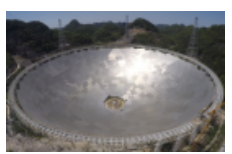

12:00

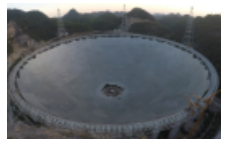

19:00

Fig. 4 The Shadow distribution under sunshine in April 16, 2016.

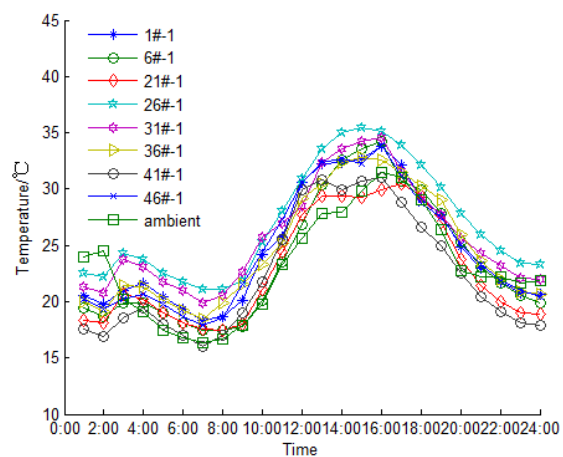

(a) The outer slider

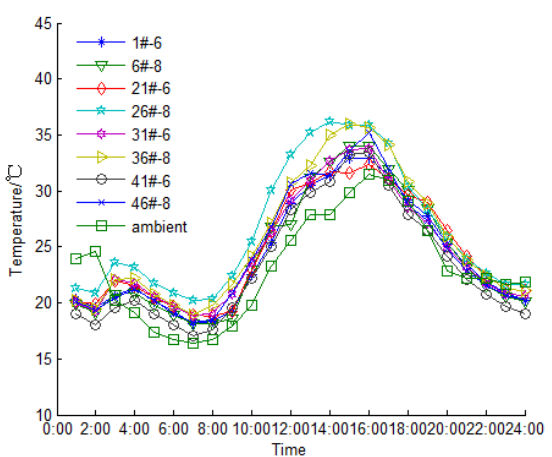

(b) The inner slider

Fig. 5 Temperature-time curve of representative points at the bottom chord bar of the outer/inner slider support of ring beam (April 16, 2016).

Compared with Fig. 4 and Fig. 5, it can be clearly indicated that the temperature variations and trends has strong correlation with the solar radiation. When the sun rises at 8:00 a.m., the shadow appears on the telescope is primarily caused by mountain block. As the sunshine shine to the corresponding ring beam of No.33 to No.49 lattice column, the temperature of ring beam cross-section increase gradually. Besides, the Fig. 5 shows that the temperature of cross-section under sunshine is higher than the area of shadow. With the rising of the sun, the shadow of the ring beams gradually disappears. No shadow area appears on the ring beam during 12:00 p.m. to 14:00 p.m. After that the shadow occurs at 16:00 p.m. While Fig. 5 indicates the temperature of the ring beam reaches to the maximum value at about 16:00 p.m. This shows that the temperature of the ring beam has a good agreement with the ambient temperature. 


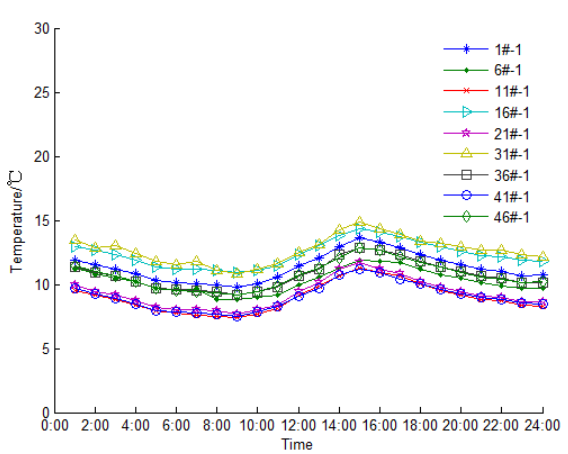

(a) The outer slider

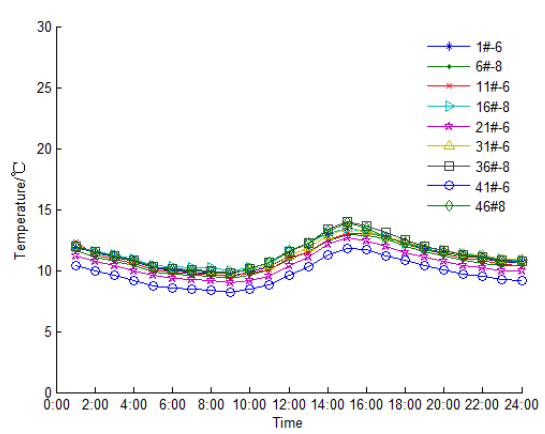

(b) The inner slider

Fig. 6 Temperature-time curve of representative points at the bottom chord bar of the outer/inner slider support of ring beam (January 10, 2016).

The Fig. 5 and Fig. 6 show that the temperature of each monitor point at cross-section of the ring beam has similar variation patterns. The temperature of structural components reaches to the minimum values normally at 8:00 a.m. of a day. Moreover, the temperature of structural components reaches maximum values at 16:00 p.m. of the day in the spring. However, the maximum values are appearing at 15:00 p.m. in winter. Moreover, no matter in what season, the temperature difference of each point at the bottom chord bar of the outer slider support of the ring beam is higher than the temperature difference of each point at the bottom chord bar of inner slider support of the ring beam. On the whole, the temperature difference between them is so small that it is not necessary to consider this parameter into the calculation of the temperature effect. Therefore, the analysis of the temperature effect can be simplified to consider the uniform temperature variation caused by seasonal temperature difference only.

\section{Statistical Relationships}

Temperature-cable Force Relationship. The cable force of cable-net is monitored by a plenty of sensors which installed on the anchors of main cables. In order to find out the effect of temperature on the cable-net, the relationship between temperature of structural components and cable force is established based on the monitored data. The data adopted in this analysis are hourly mean values from April to July in 2016. Therefore, the temperature and cable force measurement data of No.E379-E501main cable on May 11th, 2016 is selected to be studied. The comparison of cable force and structural components temperature is shown in Fig. 7.

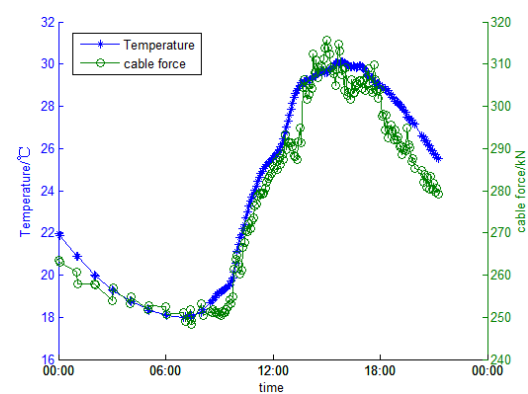

Fig. 7 Comparison of cable force-temperature.

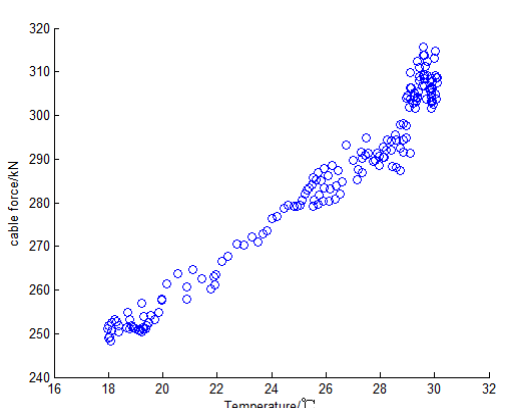

Fig. 8 Scatter plot of cable force-temperature.

Fig. 7 shows that the variation trend of cable force has a good consistency with the trend of temperature change, and the change of cable force is slightly higher than the temperature change range at noon. In order to describe the explicit relationship between cable force and temperature quantitatively, the monitored data is processed as scatter plots to observe their aggregation degree and approximate curve type, and then the statistical model is established.

Fig. 8 shows that the temperature and the cable force are closely related, and the relationship 
between them is approximated as a linear curve, so suppose that the statistical relationship model of cable force and temperature is established as follows,

$$
\mathrm{y}=\beta_{0}+\beta_{1} T+\varepsilon
$$

The model is established by numerical software MATLAB. As the result is $y=4.8846 x+158.85$, where $R^{2}$ means the correlation coefficient, in which $R^{2}=0.957$, therefore the regression model is valid.

Temperature-stress Relationship of Ring Beam. The ring beam relates the safety of the cable-net and the reflector elements. The stress and the structure temperature are monitored by lots of sensors placed in critical cross-section of the ring beam. Based on the earlier studies on the monitored data of No.1 monitor point placed at the bottom chord bar of corresponding ring beam of No.36 lattice column, the stress is increased with the increase of temperature, but not entirely consistent with temperature. Temperature is not the only factor that affects the stress of ring beam. Other effects, such as wind load, cable force, etc, are also influence the stress of ring beam [8].

Effect of Temperature on the Shape of Ring Beam. When the temperature changes, not only the ring beam structure stress and cable forces are affected, the shape of the ring beam is also changed. Based on the earlier studies, the seasonal temperature difference has great influence on the shape of ring beam. The variation and trend of deformation for ring beam with the temperature need to be analyzed based on monitored data. Therefore, the hourly mean stress value of representative points of the ring beam is used to present the effect of temperature on the shape of ring beam. Fig. 9 displays the temperature field distribution of ring beam in May 16, 2016.

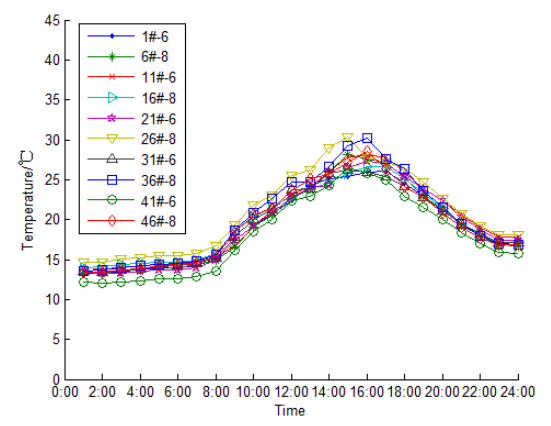

Table 2. The deformation value of ring beam.

\begin{tabular}{|l|c|c|c|}
\hline Measure time & $\begin{array}{c}\text { Ambient } \\
\text { temp }\end{array}$ & $\begin{array}{c}\text { Solar radiation } \\
\text { condition }\end{array}$ & Radius \\
\hline May 16,10:00 & $19^{\circ} \mathrm{C}$ & $\begin{array}{l}\text { Internal } \\
\text { sunshine }\end{array}$ & $250.1288 \mathrm{~m}$ \\
\hline May 16,16:00 & $26^{\circ} \mathrm{C}$ & Direct sunlight & $250.1590 \mathrm{~m}$ \\
\hline May 16,22:00 & $15^{\circ} \mathrm{C}$ & Shadow & $250.1246 \mathrm{~m}$ \\
\hline March 1,10:00 & $12^{\circ} \mathrm{C}$ & Warrington & $250.0940 \mathrm{~m}$ \\
\hline
\end{tabular}

Fig. 9 Temperature field distribution of ring beam (May 16, 2016).

The deformation response induced by temperature can be depicted by Fig. 13 and Table 3. Due to the limitation of measured data, it is hard to use function to describe the relationship between them. Comparing the Fig. 13 and Table 3 shows that the deformation of ring beam has similar variation trends with temperature. When the magnitude of temperature variation reaches to $7^{\circ} \mathrm{C}$, the magnitude of radius variation reaches to $30.2 \mathrm{~mm}$, therefore, the expansion of the ring beam in the radial direction increase with the rising of temperature gradually.

\section{Conclusion}

The variation of the stress for ring beam, shape of ring beam and cable force with temperature and the influence of the non-uniform temperature field under sunshine on the structure of ring beam have been studied based on the monitored data from the health monitoring system for the main reflector system of FAST. The significant results are presented as follows:

1) The temperature of each measurement point at cross-section of the ring beam has similar variation patterns.

2) The temperature variation has strong correlation with the solar radiation. Moreover, the temperature of cross-section under sunshine is higher than the area of shadow. The temperature of the ring beam has a good agreement with the ambient temperature.

3) As the uneven temperature difference of the ring beam under the sunshine has been proved to be very small, the analysis of the temperature effect can be simplified to consider the uniform 
temperature rise caused by seasonal temperature difference only.

4) As the temperature and the cable force response are closely related, the statistical model between them has been established.

5) The expansion of the ring beam in the radial direction has been increased with the rising of temperature gradually.

\section{References}

[1] R. D. NAN, Five Hundred Meter Aperture Spherical Radio Telescope (FAST), Sci. China: Series G: Phys. Mech. Astron. 49(2) (2006) 129-148.

[2] Q. M. WANG, M. C. WU, M. ZHU, J. X. Xue, The development of the actuator prototypes for the active reflector of FAST, SPIE Astronomical Telescopes + Instrumentation 2012 Symposium in Amsterdam, 2012/7/1-2012/7/6, Amsterdam.

[3] M. Zhu, Q. M. Wang, X. T. Zhou, X. L. Wang, J. Z. Li, Research for Construction Process Monitoring System of Main Reflector System for FAST, 2016 Eighth International Conference on Measuring Technology and Mechatronics Automation (ICMTMA), IEEE, 2016:495-498.

[4] X. F. Jin, F. Fan, S. Z. Shen, Effect of non-uniform temperature field under sunshine on the structure supporting the reflector of a large radio telescope-FAST, China Civil Eng. J. 41(11) (2008) 71-77.

[5] Y. L. Xu, B. chen, C. L. Ng, et al. Monitoring temperature effect on a long suspension bridge, Struct. Contr. Health Monitor. 17(6) (2010) 632-653.

[6] BS5400:Part2: 1978.Steel, concrete and composite bridges (Part2. Specification for loads), British Standard institute, 1978, 20-23.

[7] Y. Deng, A. Q. Li, Y. L. Ding, Research and application of correlation between beam end displacement and temperature of long-span suspension bridge, J. Highway Transport. Res. Dev. 26(5) (2009) 54-58.

[8] Q. M. Wang, M. Zhu, Q. M. Wang, He Ling. Research and application of data processing method of the health monitoring system for the main active reflector of FAST. [J/OL]. Astronomical Research \& Technology, http://www.cnki.net/kcms/detail/53.1189.p.20160921.1012.002.html. 